\title{
FRAMEWORK PARA AVALIAÇÃO DE ECOSSISTEMA EMPREENDEDOR MUNICIPAL: O CASO EXPLORATÓRIO DO MUNICÍPIO DE PETROLINA - PE
}

Deranor Gomes De Oliveira $^{1}$

Eduardo Tadayoshi Omaki ${ }^{1}$

${ }^{1}$ Universidade Federal do Vale do São Francisco 


\section{FRAMEWORK PARA AVALIAÇÃO DE ECOSSISTEMA EMPREENDEDOR MUNICIPAL: O CASO EXPLORATÓRIO DO MUNICÍPIO DE PETROLINA - PE}

Resumo

O ecossistema empreendedor é considerado um espaço que inclui intervenientes institucionais e individuais diversificados que fomentam o espírito empresarial, a inovação e o empreendedorismo local. Instrumentos avaliativos das principais dimensões do ecossistema empreendedor são desejáveis, tanto academicamente quanto para a iniciativa privada ou as políticas públicas. Não obstante sua importância, sua aplicação na realidade de municípios distantes dos grandes centros é quase inexistente. O presente trabalho resultada de um estudo de caso exploratório com objetivo de adequação e aplicação de um framework para mensuração do ecossistema empreendedor municipal, e foi desenvolvido em Petrolina-PE. O estudo observou a inexistência de bases de dados consolidadas e a dificuldade de conseguir dados confiáveis e atualizados. A título de prova de conceito foram criados 55 municípios dummy com dados extrapolados a partir do município estudado. Os dados permitiram o desenvolvimento de um índice municipal de empreendedorismo que se mostrou consistente e apto a análises.

Palavras-chave: Empreendedorismo. Indicadores de desenvolvimento. Índice municipal de empreendedorismo. Ecossistema empreendedor 
O empreendedorismo é um campo de pesquisa emergente que tem recebido muita atenção ao longo das últimas décadas. No entanto, há uma variedade de olhares sobre o que constitui precisamente o empreendedorismo e, em muitos casos, terá sido relacionado com o capital humano (FONTENELE; MOURA; LEOCADIO, 2011); com a ótica da criação e funcionamento de um negócio (GEM BARSIL, 2016); com a inovação (SCHUMPETER, 1961, SARKAR, 2010); com desenvolvimento do empreendedorismo social (YUNUS, 2010). Uma definição mais abrangente foi oferecida por Hitt et al. (2011) ao argumentarem que o empreendedorismo não envolve somente os processos de avaliação, descoberta e exploração de oportunidades, mas também o conjunto de indivíduos que descobrem, avaliam e exploram essas oportunidades.

Nessa lógica abrangente do empreendedorismo, a literatura reconhece claramente os benefícios do empreendedorismo para o crescimento e desenvolvimento econômico regional. Almeida, Valadares e Sediyama (2017) destacam que o empreendedorismo, seja por inovação ou por promoção de novos negócios, seja por necessidade ou oportunidade, por si só não é um fator de crescimento econômico, ele é um fator complementar aos outros fatores determinantes. Todavia, este estudo permitiu verificar que ele está entre os principais fatores responsáveis pelo aumento da renda. No entanto, essa visão está mais apoiada em bases teóricas do que em análises empíricas, e uma das maiores dificuldades para fazer uma análise empírica da relação entre empreendedorismo e o desenvolvimento econômico de países e regiões é a obtenção de medidas e indicadores adequados. A produção de dados sistemáticos sobre ambiente empreendedor no Brasil, e o acesso a informações confiáveis, principalmente a nível local, segundo a Endeavor Brasil (2016) é um dos maiores desafios para realizar estudos dessa natureza.

A ausência de indicadores de empreendedorismo validados, relevantes e comparáveis, na perspectiva de Borges Junior, Andreassi e Nassif (2017) pode dificultar o avanço das pesquisas em empreendedorismo e a formulação e avaliação de políticas públicas de apoio ao empreendedorismo. Ahmad et al. (2007), considera os indicadores de empreendedorismo como necessários e importantes para governos, em todas as esferas administrativas, uma vez que podem contribuir com informações privilegiadas que permitem identificar as condições atuais de determinada região e orientar a formulação de novas políticas, e também para analisar os resultados das políticas adotadas, ao evidenciar se elas resultam em mais empreendedorismo e em impactos econômicos e sociais

No longo prazo, as políticas de estímulo ao empreendedorismo provêm o desenvolvimento econômico da região, e a partir do momento em que se identificam quais são as melhores cidades, estados ou países para se empreender, Grin et al. (2012) diz-nos que é possível, também, apontar quais os caminhos que seus gestores podem seguir para melhorar o ecossistema empreendedor. Para uma empresa, manter-se viva é complicado e crescer é ainda mais desafiador em cenários competitivos. É imprescindível, então, que as cidades ofereçam as melhores condições possíveis a fim de que o empreendedorismo seja multiplicado. O ambiente de negócios está fortemente relacionado às ações do Estado, que pode criar barreiras e incentivos à atividade empreendedora. Dessa maneira, tudo o que for feito para facilitar o dia a dia do empreendedor ajudará a promover um bom ambiente de negócios que, por sua vez, gera
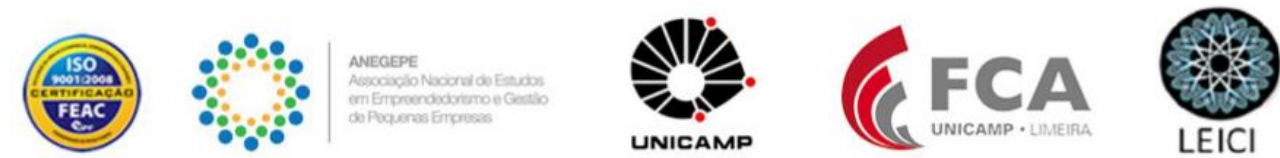
impactos positivos de desenvolvimento e impactos sociais, como a geração de renda e emprego, por exemplo.

O objetivo deste estudo consiste em avaliar o ecossistema empreendedor do município de Petrolina, Pernambuco utilizando o framework adaptado dos estudos da Endeavor Brasil 2015 e 2016 e no modelo da OCDE que trazem na sua essência variáveis consideradas determinantes do empreendedorismo. Essa construção de indicadores de empreendedorismo com recortes municipal é um segundo passo necessário para o aperfeiçoamento da formulação e avaliação das políticas públicas de empreendedorismo no Brasil, para além de identificar as principais forças, os desafios de cada cidade para que os gestores públicos e as organizações de apoio (universidades, empreendedores, mídia) possam agir de forma precisa e apontar quais os caminhos que os gestores municipais podem seguir para melhorar o ecossistema empreendedor local.

\section{Referencial Teórico}

\subsection{Indicadores dos determinantes do empreendedorismo}

Como já citado anteriormente, não existe apenas um conceito ou apenas um tipo de empreendedorismo e, dessa forma, não pode haver apenas uma medida de empreendedorismo. Vê-se no empreendedor, dessa maneira, a capacidade de combinação dos meios produtivos dos ambientes que propiciam o desenvolvimento econômico. Nesta subseção será analisada a disponibilidade e o uso de indicadores para mesurar os níveis de empreendedorismo das empresas e das condições existentes para o seu crescimento.

Um dos grandes desafios dos gestores públicos nas esferas administrativas estaduais e municipais é criar condições para que a atividade empreendedora floresça nos seus territórios. Para isso é necessário a existência de um ecossistema empreendedor que seja capaz de dar vazão ao empreendedorismo. Do ponto de vista teórico, o conceito de um ecossistema empreendedor pode ser referente, na perspectiva de Grin et al. (2012), à interação que ocorre entre um leque de intervenientes institucionais e individuais, de modo a fomentar o espírito empresarial, a inovação e o crescimento das pequenas e medias empresas. Se, por um lado, o fomento da atividade empreendedora contribui significativamente para a economia local, na geração de empregos e receitas que resultam em melhor qualidade de vida para a população, por outro lado, na perspectiva de Inácio Junior et al. (2016) as políticas públicas, a legislação e os arranjos institucionais, ainda não atingiram níveis de desempenho suficiente para uma contribuição mais efetiva para que os negócios obtenha sucesso.

Aliado a essa escassez de políticas públicas voltadas ao empreendedorismo, Grin et al. (2012), comunga das dificuldades aqui já elencadas acerca das dificuldades de encontrar indicadores consolidados e amplamente conhecidos do ecossistema empreendedor. Especificamente, no caso brasileiro, já existem alguns indicadores consolidados, embora poucos utilizados, e em construção a disposição dos gestores públicos. Possivelmente o mais popular é o estudo do Global Entrepreneurship Monitor (GEM) em parceria com o Instituto Brasileiro da Qualidade e Produtividade (IBQP), o Serviço Brasileiro de Apoio às Micro e Pequenas Empresas (SEBRAE). Entre os temas investigados pelo GEM Brasil, está um conjunto de indicadores que podem ser utilizados para análise dos fatores determinantes do empreendedorismo, em cada país, seu nível de atividade empreendedora, medir diferenças no nível de atividade empreendedora entre os países, e identificar as políticas públicas que podem favorecer a atividade empreendedora local.
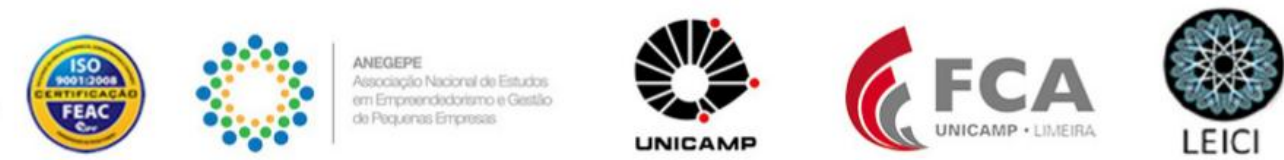
O modelo GEM reconhece que uma série de condições ambientais afeta três indicadores principais do empreendedorismo: atitudes, atividades empresariais e aspirações, e que essa combinação dinâmica produz uma nova atividade, econômica e socialmente importante, gerando empregos e riqueza (GEM BRASIL, 2016). A metodologia GEM permite análises em todas as perspectivas, dada a amplitude conceitual e operacional das condições que afetam o empreendedorismo - Entrepreneurship Framework Conditions (EFC). As EFCs refletem as principais características socioeconômicas de um país que impactam na dinâmica de criação de novos negócios. Os indicadores, medidas e taxas adotados pelo GEM faz com que países em desenvolvimento como o Brasil, por exemplo, apresente uma alta taxa de empreendedorismo (BORGES JUNIOR ET AL., 2017).

Outro estudo, não menos importante, foi desenvolvido por Ács, Szerb e Autio (2014, 2015, 2016). Os pesquisadores desenvolveram uma nova estrutura conceitual denominada National Systems of Entrepreneurship - NSE, e anexado a ele um nova metodologia de monitoramento e avaliação denominada Global Entrepreneurship Índice - GEI, com base em dados do Global Entrepreneurship Monitor e outras fontes.

Esse modelo conceitual cujo objetivo eh analisar o ecossistema empreendedor sob oticas individuais e institucionais amparados por uma metodologia que compara o desempenho dos ecossistemas empresariais é composto por três blocos de construção ou subíndices - atitudes empreendedoras, habilidades empreendedoras e aspirações empreendedoras. Atitudes empreendedoras são sobre como um país pensa sobre empreendedorismo. O segundo subíndice é sobre habilidades. Consegues fazê-lo? Você tem as habilidades? O terceiro subíndice é sobre aspirações. Você quer construir uma empresa de bilhões de dólares? Esses três subíndices representam 14 pilares, cada um dos quais contém uma variável individual e institucional que corresponde aos aspectos micro e macro-nível do empreendedorismo.

Ács, Szerb e Autio (2014) enfatizaram a relevancia da interação entre a ação empresarial e o contexto institucional. Para os autores, a ausência de iniciativa pessoal, o contexto institucional não poderá influenciar diretamente a criação de negocios de alto impacto. Ao contrario, na existência de um contexto institucional inadequado, as ações individuais não poderiam influenciar a abertura de novos negocios.

Ao analisarem de forma multifacetada o ecossistema empreendedor brasileiro à luz da teoria National Systems of Entrepreneurship - NSE, por meio da aplicação da metodologia Global Entrepreneurship Index - GEI, Inácio Júnior et al. (2016) identificaram a falta de intercâmbio entre as universidades e o ecossistema empresarial brasileiro, resultando em uma interação inadequada entre o contexto institucional e os empresários, o que implica baixas taxas de inovação, geração de empregos e desenvolvimento regional. De forma geral, o estudo mostra que a interaçao institucional é de qualidade média baixa, mesmo assim, o contexto social é o principal gargalo do ecossistema empreendedor nacional (INÁCIO JÚNIOR ET AL., 2016). As diferenças entre a qualidade do desempenho do quadro institucional e dos fatores sociais promovem o empreendedorismo de baixo impacto socioeconômico, evidenciando que o ecossistema empreendedor brasileiro apresenta baixa internacionalização de empresas, inovação em produtos e processos, formação de capital humano e de empresas de alto crescimento. Esses resultados produzem insights preciosos para os tomadores de decisão, sejam eles públicos ou privados, sobre quais fatores são mais preponderantes sobre a abertura e a evolução dos negócios.
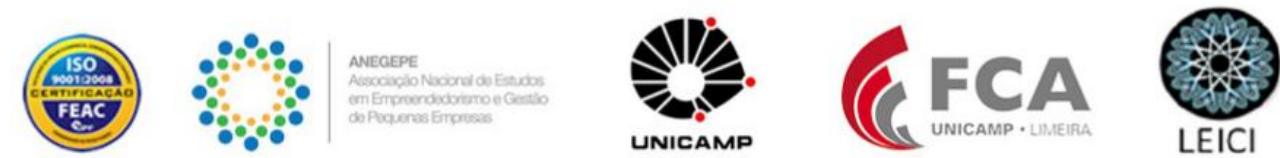
Outro caso é a da Endeavor Brasil, que criou em 2012 o Observatório do Empreendedorismo, o qual reuniu dados sobre as condições do empreendedorismo no Brasil. O modelo que a Endeavor utilizou é o da OCDE (2007), não só no que diz respeito aos tipos de indicadores, mas também nas fontes de dados utilizadas, possibilitando, dessa forma a comparação com outros países. Sobre determinantes de empreendedorismo, segundo Ahmad et al., 2007) tratam dos fatores que motivam ou impedem o desenvolvimento do empreendedorismo. Em 2014, a Endeavor Brasil passou a analisar o ecossistema empreendedor das principais cidades e criou o "Índice de Cidades Empreendedoras" para identificar aquelas que oferecem as melhores condições para empreender e como ainda esses negócios podem evoluir.

Esses estudos aqui apresentados geram dados e informações que enriquecem sobremaneira o conhecimento sobre a atividade empreendedora, além do que é encontrado nos dados oficiais dos países. Em termos gerais, como nos dizem Almeida et al. (2017), o crescimento econômico é conduzido por fatores que interagem entre si. Por exemplo, a ampliação do nível educacional em um país favorece a $\mathrm{P} \& \mathrm{D}$, que pode gerar aumento tecnológico, inovação e empreendedorismo.

\subsection{Framework dos determinantes do ecossistema empreendedor}

Foram organizados e coletados um conjunto de sete determinantes e quarenta e nove indicadores econômicos, institucionais, sociais e culturais do município de Petrolina. $\mathrm{O}$ framework adotado neste estudo segue o debate nacional liderado pela Endeavor Brasil e o debate internacional sobre avaliação de ambiente de negócios e empreendedorismo, tendo como inspiração o Framework for Entrepreneurship" (OCDE, 2007), adequado para comparar países da OCDE. Os determinantes que compõem o framework têm como fundamento a literatura internacional sobre empreendedorismo, políticas públicas e desenvolvimento econômico $\mathrm{O}$ framework podem ser mais bem compreendido a partir da figura 1.

Figura 1. Determinantes e subdeterminantes do framework para avaliar o ecossistema empreendedor municipal.

\begin{tabular}{|c|c|c|c|c|c|c|}
\hline $\begin{array}{c}\text { AMBIENTE } \\
\text { REGULATOORIO }\end{array}$ & INFRAESTRITUTIRA & & $\begin{array}{l}\text { ACESSO A } \\
\text { CAPITAL }\end{array}$ & INOVAÇAO & $\begin{array}{l}\text { CAPITAL } \\
\text { HUMANO }\end{array}$ & $\begin{array}{l}\text { CULTURA } \\
\text { EMPREENDEDORA }\end{array}$ \\
\hline $\begin{array}{c}\text { TEMPO DE } \\
\text { PROCESSOS }\end{array}$ & $\begin{array}{l}\text { TRANSPORTE } \\
\text { INTERURBANO }\end{array}$ & $\begin{array}{l}\text { DESENVOLVI } \\
\text { MENTO } \\
\text { ECONOMICO }\end{array}$ & CAPITAL & INPUTC & MAO DE OBRA & \\
\hline $\begin{array}{l}\text { CUSTO DE } \\
\text { IMPOSTOS } \\
\\
\text { COMPLEXIDA } \\
\text { DE } \\
\text { TRIBUTARIA }\end{array}$ & $\begin{array}{l}\text { CONDIÇOES } \\
\text { URBANAS }\end{array}$ & $\begin{array}{l}\text { CLIENTES } \\
\text { POTENCIAIS }\end{array}$ & $\begin{array}{l}\text { DISPONIVEL } \\
\text { VIA DIVIDA } \\
\text { ACESSO A } \\
\text { CAPITAL } \\
\text { DE RISCO }\end{array}$ & OUTPUTS & $\begin{array}{l}\text { BASICA } \\
\text { MAO DE OBRA } \\
\text { QUALIFICADA }\end{array}$ & $\begin{array}{l}\text { IMAGEM DO } \\
\text { EMPREENDE } \\
\text { DORISMO }\end{array}$ \\
\hline
\end{tabular}

\subsubsection{Ambiente regulatório}

Esse determinante engloba as obrigações que as empresas devem cumprir, frente as leis e diretrizes que regulamentam o seu funcionamento, contemplando questões fiscais, fundiárias, trabalhistas, etc. Para esse determinante, a avaliação se dá por meio de oito indicadores distribuídos por três subdeterminantes: i) tempo de processos, que contempla o Tempo de abertura de empresas (em dia), Tempo para regularização de imóveis (em dia) e a Taxa de congestionamento em tribunais, ii) custo de impostos, que contempla a Alíquota média do 
ICMS, a Alíquota média do IPTU, e iii) complexidade tributária, contemplando a Número médio de incentivos fiscais estaduais e o número de atualizações tributarias.

Pohlmann e Alves (2004, p. 233) afirmam que a regulação "pode ser entendida como um conjunto de normas coercitivas, emanadas do Estado ou de órgão com poderes para tanto, relativas a determinada atividade ou área do conhecimento". Importante analisar que, no contexto de um pais que exibe um ambiente regulatório extremamente complexo, burocratizado e onde os impostos não são baixos, os subdeterminantes supra citados podem apresentar comportamentos distintos, em que podem interferir na regularização de um empreendimento. Para Isenberg (2010) o governo tem um papel fundamental para as empresas na regulação de um conjunto de normas e regulamentos que podem facilitar o processo empreendedor e diminuir a burocracia. De forma geral, Grin et al. (2012) indicam que as políticas regulatórias afetam positivamente o ambiente empreendedor e, portanto, os empreendedores de alto impacto e por estilo de vida. O bom ambiente regulatório gera efeitos positivos sociais e de desenvolvimento. Já as políticas de estímulo, estão relacionadas a ações que promovem prioritariamente a atividade empreendedora de alto impacto (GRIN ET AL., 2012).

Sem a análise do espaço regulatório, considerando suas particularidades atuantes em cada empreendimento, para o estabelecimento de indicadores de competitividade, de crescimento e de sustentabilidade das organizações, dificilmente o negócio poderá prosperar e se alicerçar no mesmo espaço de mercado que as outras empresas.

\subsubsection{Infraestrutura}

Um conjunto de elementos ou serviços considerados necessários para que uma atividade produtiva se desenvolva efetivamente. É a base material de uma sociedade e a que determina a estrutura social, o desenvolvimento e sua mudança social, incluindo, nesses níveis, as forças produtivas e as relações de produção existentes (ENDEAVOR BRASIL, 2015). Quanto melhores forem as condições logísticas, de produção e das comunicações de uma cidade, menores serão os custos de produção e maior será a eficiência das operações.

A avaliação desse determinante é realizada por meio de oito indicadores divididos em dois grupos de subdeterminantes: o transporte Interurbano que contempla a conectividade da cidade via rodovias $(\mathrm{km})$, o número de passageiros em voos diretos por ano, a distância do porto mais próximo $(\mathrm{Km})$, e as condições urbanas incluem os domicílios com acesso à banda larga fixa, o preço médio do $\mathrm{m}^{2}$, Custo de energia elétrica, a taxa de homicídios e o índice de fluidez urbana. Esses indicadores estão ligados diretamente aos custos para os empreendedores, interferindo em sua competitividade.

\subsubsection{Mercado}

Diz respeito ao acesso dos empreendedores ao mercado com suas ideias, seus produtos, ou seus serviços, seja nos modelos Business-to-Consumer (B2C), Business-to-Business (B2B) ou Business-to-Government (B2Gov). Mais especificamente, trata-se de uma análise sobre a situação dos mercados nas cidades brasileiras. Cidades com mercados maiores tendem a atrair mais empreendedores, principalmente, se o negócio exigir vendas presenciais ou estiver no início das operações. Do contrário, cidades com mercados menores forçam os empreendedores a procurarem novas formas de comercializar, ultrapassando novas fronteiras, que podem incluir, inclusive, o mercado externo.

Empreendedores com ideias arrojadas e inovadoras; mão de obra altamente qualificada; infraestrutura e ambiente regulatório favoráveis: tudo isso é positivo e bem-vindo ao
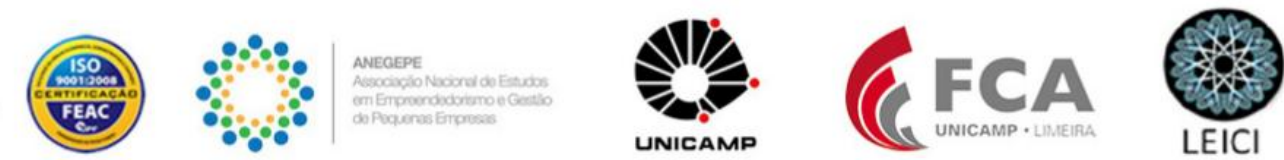
ecossistema empreendedor municipal, mas não surtirá efeito algum se não houver mercado para os serviços e produtos oferecidos. A avaliação desse índice foi realizada por meio de dois conjuntos de indicadores: o subdeterminante desenvolvimento econômico, que inclui o PIB total, o crescimento médio real do PIB nos últimos 3 anos, a proporção de empresas exportadoras com sede na cidade, o PIB per capita - fatores que impactam o potencial e o horizonte do crescimento da empresa e o subdeterminante clientes potenciais das empresas: o consumidor final (B2C), por meio do PIB per capita; as empresas (B2B), medindo-se a, proporção entre grandes/médias empresas e médias/pequenas; e o gasto público direcionado aos investimentos e compras dos governos municipais (B2Gov), lembrando do papel do governo como um importante consumidor.

\subsubsection{Acesso a Capital}

O dinheiro é a base para se iniciar todo sistema produtivo; logo, obter investimentos é fator primordial para todas as empresas que estão começando, ou em processo de crescimento. o acesso a capital para se financiar um empreendimento é um dos maiores obstáculos para a maioria esmagadora de empreendedores brasileiros faltando muito para se chegar a um nível ideal competitivo com outras nações (GEM BRASIL, 2016). O relatório ICE 2016 da Endeavor Brasil aponta as cidades que possuem uma maior facilidade em financiar os negócios. Entre as cidades pesquisadas, São Paulo destaca-se no índice apresentando mecanismos de acesso a capital, que o coloca no topo do ranking de 2016. Em nenhum outro lugar do país o capital é tão presente. E os motivos para o resultado são contundentes, a começar pelo acesso a capital por meio de dívidas: São Paulo empresta mais de 22 vezes o valor do seu PIB todos os anos (são R \$ 11 trilhões em empréstimos), quase 50\% mais (proporcionalmente) do que a segunda colocada, Porto Alegre (ENDEAVOR BRASIL, 2016).

A avaliação se deu por meio de indicadores distribuídos entre dois subdeterminantes: i) Capital disponível via dívida que inclui as operações de crédito do município (em relação ao PIB) e ii) Acesso a capital de risco utilizando o Capital poupado per capita como principal indicador.

\subsubsection{Inovação}

De acordo com a Lei 10.973/04, “inovação é a introdução de novidade ou aperfeiçoamento no ambiente produtivo ou social que resulte em novos produtos, processos ou serviços". É a exploração, com sucesso, de novas ideias. A inovação, ainda, deve ser uma característica inata ou, ao menos, trabalhada pelo empreendedor e por aquele que busca se desenvolver como um. Inovar não significa apenas criar aquilo que inexiste. É de certeza mais do que criar produtos ou serviços completamente novos. Segundo Sarkar (2010), é aquilo que oferece ao consumidor um novo benefício ou que acrescente algo que ainda não tenha sido oferecido anteriormente.

Para avaliar os níveis desse determinante adotou-se as recomendações de parte do modelo adaptado pela Endeavor Brasil. Ou seja, a medição da inovação pode ocorrer com a análise de dois subdeterminantes: inputs (os insumos para a inovação acontecer) e os outputs (os resultados da inovação) capturados por oito indicadores, quais sejam, Proporção de Mestres e Doutores atuando na cidade, Proporção de funcionários nas áreas de C\&T, Infraestrutura tecnológica, Contratos e Concessões, Proporção de Instituições que trabalham a Inovação nas Empresas, Proporção de Empresas com Patentes, Tamanho da economia criativa e Tamanho das empresas TIC.
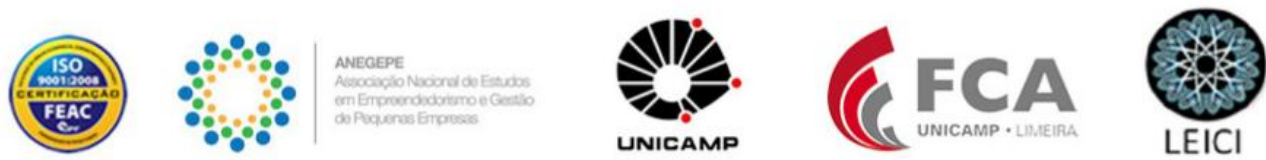


\subsubsection{Capital humano}

O Capital Humano refere-se à riqueza que se pode ter em uma fábrica, empresa ou instituição em relação à qualificação dos seus funcionários; também pode estar relacionado com aspectos e elementos sociológicos, tais como o acesso aos meios de capacitação de um grupo de pessoas, a alfabetização, a projeção futura de certas carreiras ou trabalhos, a possibilidade de uma vitória de acordo com o nível de educação, entre outros.

Para medir o capital humano, foram selecionados dois tipos de subdeterminantes educacionais, que mostram a atual qualidade do ensino das cidades, e os de estoque, que apresentam as características de formação da população adulta: i) acesso e qualidade da mão de obra básica. Esses revelam o cenário atual da educação nos locais, apontando a quantidade e a qualidade da formação da população a entrar no mercado de trabalho nos próximos anos. É o caso do Nota do IDEB nos anos finais, Proporção de pessoas com 25 ou mais com pelo menos o ensino Médio completo, Proporção de matrícula no ensino médio, Nota média no ENEM, Proporção de matrículas no ensino técnico profissionalizante e ii) acesso e qualidade da mão de obra qualificada inclui a proporção de pessoas com 25 anos ou mais com, pelo menos, o ensino superior completo, a proporção de alunos matriculados em cursos de alta qualidade, o número de alunos matriculados em cursos de alta qualidade e o custo médio de salários de dirigentes.

A contribuição do capital humano para o processo de desenvolvimento econômico das nações, segundo Fontenele et al. (2011), já foi objeto de vários estudos desde a década de 1960. Entretanto, a atualização do tema começou na segunda metade dos anos 1990, com a necessidade de analisar o papel da influência do capital humano e do empreendedorismo no processo de desenvolvimento econômico. Da mesma forma Martin et al. (2012) reforçaram que pesquisadores do empreendedorismo têm centrado esforços na relação entre o capital humano e os resultados empresariais em vários níveis de análises

\subsubsection{Cultura empreendedora}

A palavra cultura está estritamente associada aos valores e hábitos mantidos por determinada sociedade. $\mathrm{O}$ índice de Cultura empreendedora ajuda a captar as percepções que as pessoas têm em relação ao empreendedorismo, seja num plano pessoal, de uma cidade, ou do país, ao mesmo tempo em que ajuda a compreender o desenvolvimento e a performance do contexto institucional empreendedor pode se manifestar da mais variadas formas.

$\mathrm{Na}$ construção do índice, o foco foi a imagem do empreendedor e para avalia-lo foi utilizado oito indicadores, quais sejam, Status e respeito, Histórias sobre novos empreendedores bem sucedidos na mídia, Empreendedores exploram seus funcionários, Dificuldade de apoiar pela insegurança financeira, Desenvolvimento do Brasil depende muito dos empreendedores, Empreender, na minha cidade, é bastante complicado, Na sua cidade, a maioria das pessoas considera que abrir um negócio é uma boa opção e Conhece alguém pessoalmente que abriu um negócio nos últimos dois anos.

A imagem do empreendedorismo traduz a imagem que a população de cada uma das cidades tem da atividade empreendedora e dos empreendedores em si, refletindo a possibilidade de o impulso empreendedor se manifestar com mais intensidade, dadas as devidas condições para isso. Trata-se, portanto, de um elemento ligado à cidade e não a um ou outro segmento (Endeavor Brasil, 2016). Logo, não necessariamente reflete a real presença de empreendedores em cada região, que pode ser medida de diversas outras formas.

\section{$3 \quad$ Metodologia}
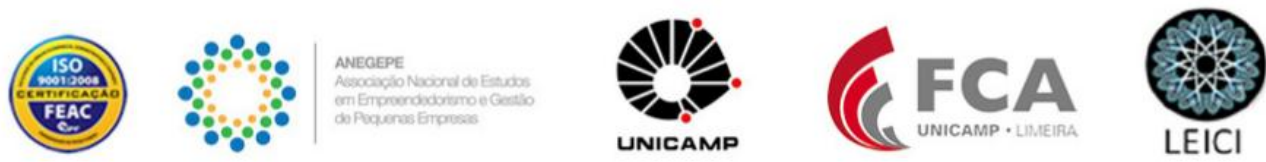


\subsection{Delineamento de pesquisa}

Formalmente, segundo Cooper e Schindler (2003, 128-143), o estudo que norteou o presente trabalho pode ser classificado como um estudo de caso exploratório, ex post facto, descritivo, transversal, de natureza quantitativa e qualitativa.

Quanto ao objetivo do estudo, pretendeu-se adequar e aplicar um framework para mensuração do ecossistema empreendedor municipal fora do eixo das capitais e grandes centros urbanos. Para tanto se almejou estudar, analisar, aplicar e adaptar um framework já consolidado e aplicado nacionalmente nas capitais, mas em um contexto de municípios interioranos e fora dos eixos dos grandes municípios e centros urbanos, mensurando para tal o ecossistema empreendedor do município de Petrolina - PE. A escolha do município foi não aleatória e de conveniência.

\subsection{Coleta de dados}

A fase de coleta do estudo foi desenvolvida no segundo semestre de 2017, e foi dividida em 3 partes:

1. Pesquisa bibliográfica prévia, para nivelamento e o desenvolvimento do lastro teórico e adequação ao contexto do estudo;

2. Pesquisa documental, para coleta e construção da base de dados quantitativos; e

3. Pesquisa tipo survey, realizada em paralelo à pesquisa documental, objetivava mensurar as atitudes de uma amostra da população do município para o determinante 'Cultura Empreendedora', para suprir uma lacuna de dados.

Como limitações do estudo, convém observar alguns pontos:

- Uma limitação digna de observação é a ausência ou dificuldade de obtenção de dados confiáveis, consolidados e atualizados. A amplitude e diversidade do índice em termos de determinantes e suas dimensões implicam na necessidade de dados diversos em quantidade e natureza, muitos dos quais não são disponibilizados de modo conveniente nem atuais, ou nem mesmo são disponibilizados. Muitos dados são defasados em até três anos. Entretanto, vários dos dados sofrem influência de fatores macro ou meso ambientais e tendem a não sofrem variações bruscas em horizontes de um ou dois anos, o que permite seu uso no que se pretendeu no presente estudo.

- $\quad$ Como limitação da fase de pesquisa survey, a absoluta aleatoriedade na distribuição dos respondentes, bem como sua estrita representatividade populacional no âmbito municipal não foi alcançada por limitações de informações e recursos, e, portanto, os achados não podem ser tomados como um retrato estritamente fiel da população, mas como um estimador exploratório para o fim pretendido, o teste de conceito.

\subsection{Unidade de estudo}

O município de Petrolina situado no interior do estado de Pernambuco, região Nordeste do Brasil e na Mesorregião do São Francisco Pernambucano, distante $712 \mathrm{~km}$ a oeste de Recife, capital estadual, população estimada (2017) de 343219 hab. - quinto município mais populoso do estado, um Produto Interno Bruto de R\$ 5230471 mil, - sétima economia do estado, centésima septuagésima quarta economia do Brasil e Índice de Desenvolvimento
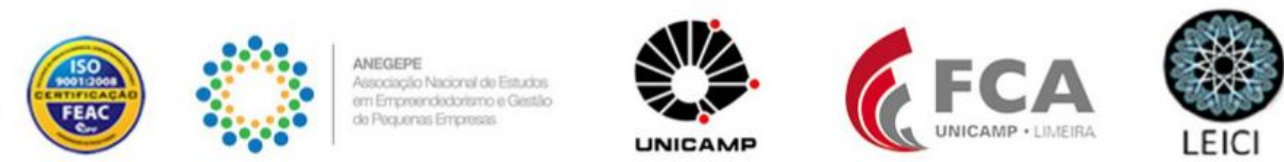
Humano Municipal (IDHM) 0,697, (IBGE, 2014), é nossos ecossistema empreendedor de estudo.

Petrolina se destaca, entre outros aspectos, nos itens desenvolvimento e economia. Se tornou um polo centralizador, ofertando serviços disponibilizados apenas em grandes centros, fator que atrai pessoas de várias localidades do seu entorno. Os resultados são vistos a partir da sua importância na participação do PIB estadual, além de figurar mundialmente como a $3^{\circ}$ maior produtora de frutas e $20^{\circ}$ maior exportadora. A fruticultura é uma das maiores atividades econômicas da cidade, responsável pelo aumento populacional no Vale do São Francisco, que atrai para a região pessoas em busca de novas perspectivas em negócios.

O crescimento de Petrolina fez com que o desenvolvimento econômico da cidade não ficasse concentrado apenas na fruticultura, atraindo novos investimentos em diversas áreas gerando emprego e renda em outros segmentos como administração pública, construção civil, comércio e serviço. No entanto o ecossistema empreendedor do município, como tantos outros, apresenta desafios e gargalhos que carecem de estudos e debates para serem superados e possam contribuir para políticas públicas voltadas para o empreendedorismo.

\subsection{Tratamento dos dados}

Quase todos indicadores utilizados para compor o índice têm medidas, escalas e grandezas diferentes, os quais não são passíveis de cálculo direto ou causam distorções, Como por exemplo, na possibilidade de somar "dias (tempo)" com "reais (R\$)". Por tal motivo fez-se necessário nivelar os dados em uma unidade de medida comum de modo que pudessem ser comparadas. Assim, cada indicador passou pelo processo de transformação baseado em parâmetros estatísticos chamado de 'normalização'. Tal processo permite que variáveis usualmente não comparáveis, em dimensões ou grandezas, possam ser comparadas e calculadas sem causar distorções.

Convém observar que o processo de normalização só faz sentido quando os dados fazem parte de um 'pacote' de múltiplos casos. Assim, para fins desse teste de conceito, para se comparar os dados reais do Município de Petrolina-PE, foram criados dados para 55 cidades dummy, por meio de procedimentos computacionais de geração de dados aleatórios.

Após a tabulação dos dados, foi feita a análise de cada indicador e foram identificadas e diferenciadas as variáveis "positivas" e "negativas", conforme elas se associavam positiva ou negativamente com os DETERMINANTES que viabilizam e fornecem um ambiente positivo para o empreendedorismo. Em seguida, cada INDICADOR foi padronizado e recalculado, conforme fosse positivo ou negativo.

Após a normalização, uma vez passíveis de serem comparados entre si, os diversos indicadores foram agregados e computadas suas médias - uma para cada determinante - e em uma média geral, que é o valor do ÍNDICE MUNICIPAL DE EMPREENDEDORISMO - IME.

A partir deste início, a intenção é que a base de dados seja expandida cada vez mais por dados de municípios reais, aumentando a precisão e relevância do índice e suas aplicações.

\section{$4 \quad$ Resultados}

\subsection{O Índice Municipal de Empreendedorismo}

Para a construção do Índice Municipal de Empreendedorismo foi elaborado um framework adequado à realidade do município de Petrolina, Estado de Pernambuco, e em sintonia com as ferramentas utilizadas pela Endeavor Brasil. O framework está estruturado a 
partir de sete pilares, ou determinantes, já descritos no quadro teórico, que formam os eixos temáticos do estudo e são a base do índice final do empreendedorismo municipal.

Os dados foram provenientes de diversas fontes e métodos de coleta, cada qual adequado a sua natureza e disponibilidade. Os dados foram coletados de documentos oficiais de órgãos governamentais, tais como IBGE, Secretarias de Assuntos Estratégicos, Banco Central, BNDES, Secretarias do município de Petrolina, Sebrae, Ministério da Educação - MEC, Etc. Para o caso do determinante Cultura Empreendedora que não havia indicadores disponíveis em fontes públicas, os dados foram obtidos com indicadores próprios por meio de uma pesquisa de campo. O Quadro 2 sintetiza a disponibilidade dos indicadores por domínio, público, privado ou inexistente, a quantidade de indicadores utilizados por cada domínio, e por fim, o posicionamento dos determinantes no âmbito dos domínios.

Quadro 2 -Resumo da disponibilidade dos indicadores por domínio

\begin{tabular}{|l|l|l|l|}
\hline $\begin{array}{l}\text { Disponibilidade do } \\
\text { Indicador }\end{array}$ & $\begin{array}{l}\text { Indicador Público e } \\
\text { Disponível }\end{array}$ & $\begin{array}{l}\text { Indicador sob domínio } \\
\text { de terceiros }\end{array}$ & $\begin{array}{l}\text { Inexistente } \\
\text { Obtida por pesquisa }\end{array}$ \\
\hline Indicadores & $\mathbf{2 9}$ & $\mathbf{1 1}$ & $\mathbf{8}$ \\
\hline Determinantes & $\begin{array}{l}\text { - Mercado } \\
\text { - Capital Humano } \\
\text { - Infraestrutura } \\
\text { - Inovação }\end{array}$ & $\begin{array}{l}\text { - Acesso A Capital } \\
\text { - Ambiente. Regulatório } \\
\text { • Inovação }\end{array}$ & $\begin{array}{l}\text { Cultura } \\
\text { Empreendedora }\end{array}$ \\
\hline
\end{tabular}

\subsection{Teste de Conceito do Índice Municipal de Empreendedorismo}

Conforme explicado anteriormente, após a coleta, os dados do município de Petrolina PE foram tabulados no software estatístico open source PSPP e em planilhas eletrônicas de dados open source LibreOffice. Nas planilhas foram criadas fórmulas para geração de dados aleatórios em três camadas de iteração e variação limitada a $\pm 10 \%$ por iteração. Essas fórmulas foram então aplicadas sobre os valores do município de Petrolina, gerando 60 conjuntos de dados, dos quais foram descartados os 5 conjuntos de dados dos extremos. Esses conjuntos de dados foram então transportados para o PSPP para transformações, estatísticas de tendência central, distribuição e rankings.

No PSPP, cada uma das variáveis - as quais representam os subdeterminantes - de todos os conjuntos de dados foi normalizada e seus valores de $\mathrm{z}$ score foram salvos como uma nova variável, a qual serviu de base para as médias de cada determinante e o cálculo do índice municipal de empreendedorismo e por fim, analisada a posição de Petrolina-PE nesse cenário comparativo com as demais cidades dummy. A tabela 3, a seguir, mostra os valores de cada um dos determinantes que compõe o índice, bem como o próprio Índice Municipal de Empreendedorismo. 
Tabela 3: Prova de conceito - Valores dos determinantes e IME de Petrolina - PE.

\begin{tabular}{lll}
\hline Determinantes & Variável & Valor** \\
\hline Ambiente Regulatório & D1_AMB_REG & $-14,95$ \\
\hline Infraestrutura & D2_INFRA & $-03,89$ \\
\hline Mercado & D3_MERC & 08,38 \\
\hline Acesso a Capital & D4_ACESSOCAPITAL & 11,67 \\
\hline Inovação & D5_INOV & 20,34 \\
\hline Capital Humano & D6_CAP_HUMANO & 17,08 \\
\hline Cultura & D7_CULT & 00,33 \\
\hline & & \\
\hline Índice Municipal de Empreendedorismo & & 05,47 \\
\hline
\end{tabular}

Nos dados computados, detalhados na tabela anteriormente apresentada, observa-se que, comparativamente, o determinante Ambiente Regulatório é o que mais impacta negativamente para a posição do IME, seguido pela Infraestrutura. Ambos fatores, neutralizam muito da contribuição positiva dos determinantes Inovação e Capital Humano.

A figura 4, a seguir, mostra em um gráfico os valores do IME para Petrolina e cada um dos municípios dummy.

Figura 4: Prova de conceito - IME de Petrolina e municípios dummy

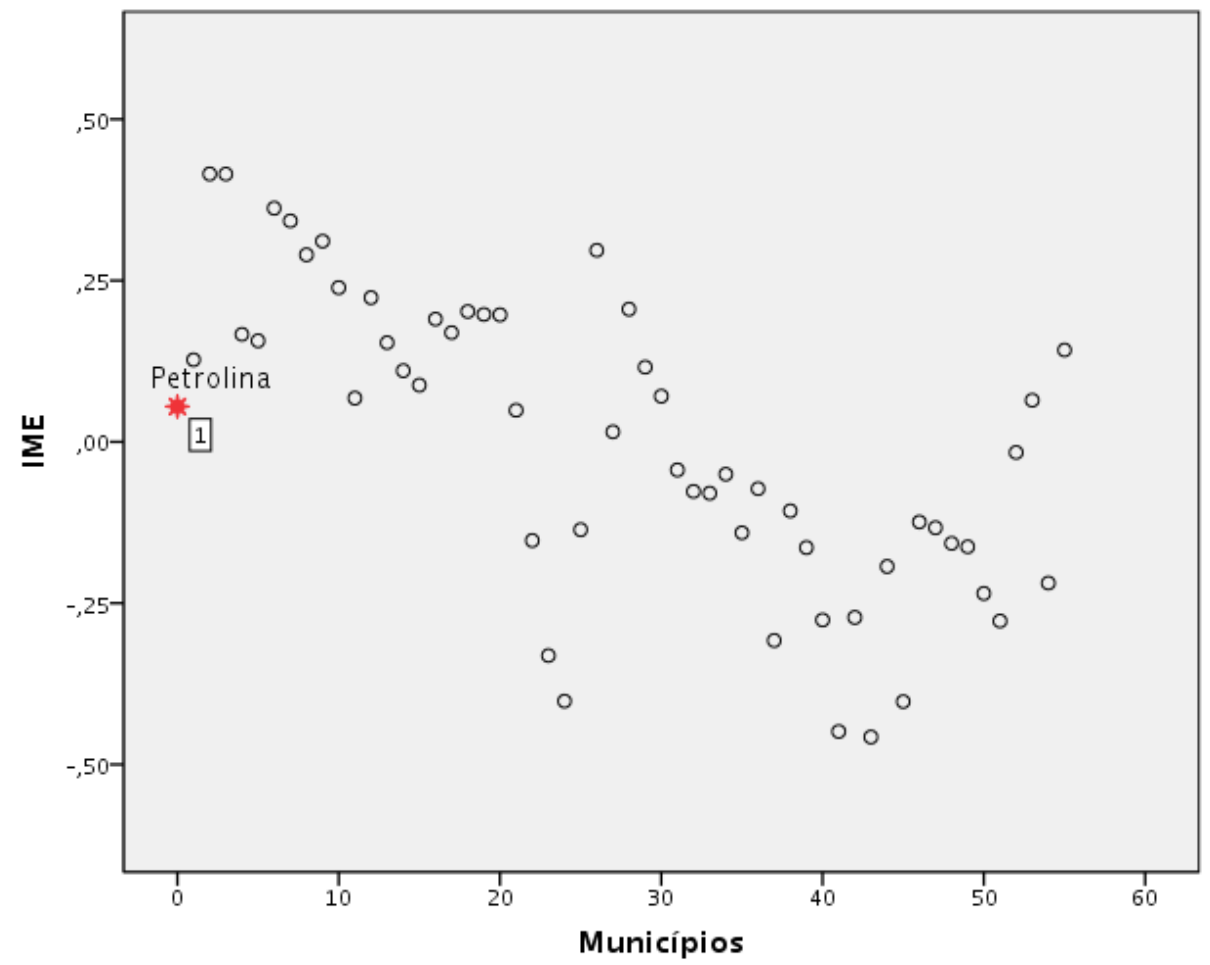

Ainda, testou-se pela existência de correlação entre os valores de PIB e os IMEs calculados no cenário do estudo. A tabela 5, a seguir, mostra os resultados do teste Ro de 
Spearman. Observe-se o valor do teste de significância de 0,051 , e o coeficiente de correlação de 0,262 .

Tabela 5: Prova de conceito - Testes de correlação entre o PIB e o IME

\begin{tabular}{|c|c|c|c|}
\hline \\
\hline \multicolumn{3}{|c|}{ Ro de Spearman } & IME \\
\hline \multirow{3}{*}{$\begin{array}{l}\text { PIB Per } \\
\text { capita } \\
\text { municipal }\end{array}$} & & Coef. Corr. & 0,262 \\
\hline & Sig. (2 tail) & 0,051 & \\
\hline & $\mathrm{N}$ & 56 & \\
\hline
\end{tabular}

A figura 6, a seguir, mostra o gráfico de distribuição do teste de correlação de spearman entre as variáveis IME e PIB. Note-se a reta e a equação que sinalizam uma correlação positiva a 0,262 .

Figura 6: Prova de conceito - Correlação entre PIBs e IMEs

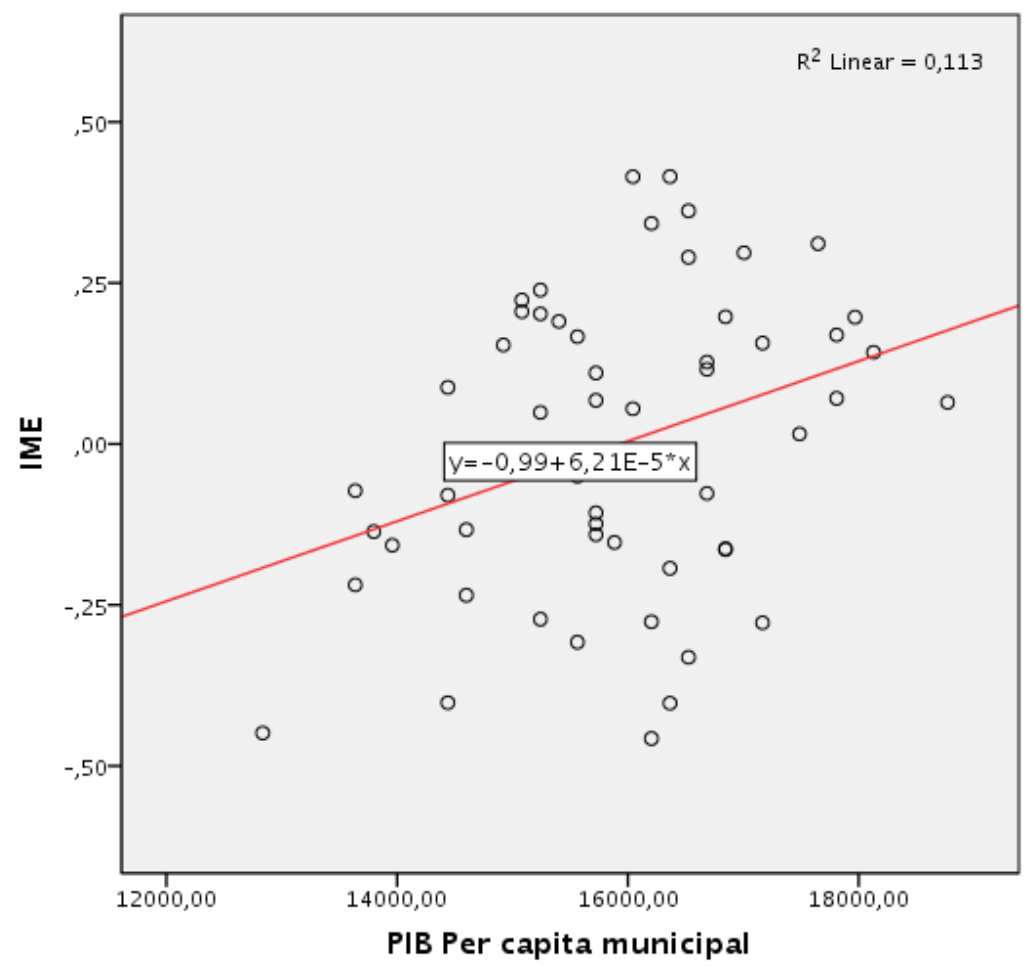

\section{$5 \quad$ Considerações finais}

Em uma visão geral, percebeu-se a carência em termos de instrumental analítico validado em campo dos ambientes e fatores que impactam especificamente o comportamento empreendedor, entretanto, os autores entenderam essa carência como um campo amplo de oportunidades de estudos formais, com estatística e matemáticas robustas. 
Como prova de conceito, percebeu-se tanto a viabilidade quanto o potencial do método no cálculo de um índice, bem como o potencial do próprio índice uma vez que os dados dos municípios permitiram o desenvolvimento de um índice municipal de empreendedorismo que se mostrou consistente e apto a análises que permitiriam nortear ações de empreendedores privados ou políticas públicas, sugerindo-se assim a continuidade e aprofundamento dos estudos por essa via.

Os resultados deste trabalho poderão ajudar a determinar, por meio de estudos formais posteriores, mais amplos - e com mais recursos - uma análise baseada em dados empíricos, quais das variaveis em estudo são preponderantes no surgimento de novos negocios e nas condiçoes de evoluçao dos mesmos, e apontando para as cidades que ofertam as melhores condições de empreender.

Como achados colaterais do estudo, no que tange ao processo de obtenção das informações, observou-se: a) a inexistência de bases de dados consolidadas b) a extrema dificuldade de conseguir dados confiáveis e/ou atualizados. c) que mesmo bases de dados governamentais têm defasagem. d) que muitos órgãos não disponibilizam os dados de modo organizado e consolidados porque não os consolidam. Desses, a questão de se não se ter os dados consolidados e disponíveis, principalmente para aqueles que deveriam estar trabalhando para promover o desenvolvimento merece atenção, visto que, se é que estão tomando decisões nesse tocante, em que se baseiam?

\section{Referências}

Ács, Z. J.; Szerb, L.; Autio, E. Global Entrepreneurship Index 2015. London: Amazon Books, 2015.

Global Entrepreneurship Index 2016. London: Amazon Books, 2016.

Ahmad, Nadim \& Hoffmann, Anders N. A Framework for Addressing and Measuring Entrepreneurship. OCDE, 2007. Disponível em: <http://www.oecdilibrary.org/economics/aframework-for-addressing-and-measuringentrepreneurship_243160627270>. Acesso em: 01 nov. 2017.

Almeida, F. M., Valadares, J. L., Sediyama, G. A. S. Revista de Empreendedorismo e Gestão de Pequenas Empresas. v. 6, n.3, p. 466-494, Set/Dez, 2017.

Borges Junior, C. V., Andreassi, T., \& Nassif, V. M. J. Editorial: - (A Falta de) Indicadores de Empreendedorismo no Brasil. Revista de Empreendedorismo e Gestão de Pequenas Empresas, v. 6, n. 3, pp. 1-9, 2017.

Carvalho, L. M. C., Viana, A. B. N. e Mantovani, D. M. N. 2016. Revista de Administração, Contabilidade e Economia da Fundace. v. 7, n. 1, Ed. Esp. Ecossistemas de Inovação e Empreendedorismo, p. 84-101.

Cooper, D. R., \& Schindler, P. S. Métodos de Pesquisa em Administração. $7^{\mathrm{a}}$ ed. Porto Alegre, Rio Grande do Sul, Brasil: Bookman, 2003.

Endeavor Brasil. Índice de Cidades Empreendedoras. São Paulo: Endeavor Brasil, 2016. Endeavor Brasil. Burocracia nos Negócios: os Desafios de um Empreendedor no Brasil. São Paulo: Endeavor Brasil, 2015. Disponível em <http://info.endeavor.org.br/burocracianobrasil> Acesso em: 01.nov. 2017. 
Endeavor Brasil. "Cultura Empreendedora no Brasil: o potencial para empreender com alto impacto". São Paulo: Endeavor Brasil, 2015. Disponível em <http://info.endeavor.org.br/culturaempreendedoranobrasil>. Acesso em: 01 nov. 2017.

Endeavor Brasil \& IBGE. Estatísticas de Empreendedorismo. São Paulo: Endeavor Brasil, 2013. Disponível em: <http://info.endeavor.org.br/estatisticas-de-empreendedorismo>. Acesso em: 01 nov. 2017.

Fontenele, R. E. S., Moura, H. J., Leocadio, A. L. Capital humano, empreendedorismo e desenvolvimento: evidências empíricas nos municípios do Ceará. Revista de Administração Mackenzie, v. 12, n. 5. pp. 182-208., 2011.

Global Entrepreneurship Monitor. Empreendedorismo no Brasil. Coord. Greco, Simara M. de S. S.. Curitiba: IBQP, 2017. 208 p. il.

Grin, E. J., Acosta, F. G., Sarfati, G., Alves, M. A., Peinado Gomes, M. V.; Spink, P. K. Desenvolvimento de Políticas Públicas de Fomento ao Empreendedorismo em Estados e Municípios/Centro de Estudos em Administração Pública e Governo, Centro de Empreendedorismo e Novos Negócios. São Paulo: Programa Gestão Pública e Cidadania, 2012. 52 p.

Inácio Júnior, E., Autio, E., Morini, C., Gimenez, F. A. P., \& Dionisio, E. A. 2016. Analysis of the Brazilian entrepreneurial ecosystem. Ano 14 n. 37 - Edição Especial: Empreendedorismo e Inovação. Disponível em $:<\mathrm{http}: / / \mathrm{dx}$. doi.org/10.21527/22376453.2016.37.5-36>. Acesso em: 01 nov. 2017.

Hitt, M. A., Ireland, R. D., Sirmon, D. G., Trahms, C. A., Strategic entrepreneurship: creating value for individuals, organizations, and society. Academy of Management Perspectives. v. 25, n. 2, pp. 57-75, 2011.

Isenberg, D. J. How to start an Entrepreneurial Revolution. Harvard Business Review, v. 88, n. 6, p. 40-51, 2010.

Martin, B., Nightingale, P., Yegros-Yegros, A. Science and technology studies: exploring the knowledge base. Research Policy. v. 41, n. 7, pp. 1182-1204, 2012.

Pohlmann, M. C.; Alves, F. Regulamentação: Teoria avançada da contabilidade. São Paulo: Atlas, 2004. pp. 233-273.

Shane, S. A., Venkataraman, S., The promise of Entrepreneurship as a field of research. Academy of Management Review. v. 25 n. 1,pp. 217-226, 2000.

Sakar, S. Empreendedorismo e inovação. $2^{a}$ ed. Lisboa: Escolar, 2010.

Schumpeter, J. A. Teoria do Desenvolvimento Econômico. Tradução L. Schlaepfer. Rio de Janeiro: Fundo de Cultura, 1961.

SERVIÇO BRASILEIRO DE APOIO AS MICRO E PEQUENAS EMPRESAS - SEBRAE.

Souza, E., et al. O Reflexo da Carga Tributária na Mortalidade das Microempresas. Anais do $110^{\circ}$ CONEX. Anais. Ponta Grossa: UEPG: 2015.

Yunus, M. Criando um negócio social: Como iniciativas economicamente viáveis podem solucionar os grandes problemas da sociedade. Rio de Janeiro: Elsevier, 2010. 